Palaeogeography, Palaeoclimatology, Palaeoecology

Elsevier Publishing Company, Amsterdam-Printed in The Netherlands

\title{
Editorial
}

\section{PALYNOLOGY AND ENVIRONMENTAL GEOLOGY}

\author{
A. A. MANTEN
}

Secretary and Editor, Second International Conference on Palynology, Cortezlaan 9, Utrecht (The Netherlands)

(Received March 28, 1967)

\section{SUMMARY}

A brief survey of the possibilities and problems of palynology as a contributor to the progress of palaeogeography, palaeoclimatology and palaeoecology is presented. Also shown is how these fields and other branches of the earth sciences which contribute to environmental geology may, in their turn, help to advance palynology. The paper constitutes an introductory text to a collection of papers which fill a special issue of the journal Palaeogeography, Palaeoclimatology, Palaeoecology, entitled "Palynological contributions to environmental geology".

\section{INTRODUCTION}

Palynology is just one of the many specialized branches of science which are found today. It cannot exist without support from several other branches, but can also render very useful services to these other branches. An advantage is that it concerns itself with very small entities, such as pollen grains, spores and other organic microremains. The great abundance and ubiquity of these in sedimentary deposits and the fairly constant characteristics of spores and pollen grains of a particular species give palaeopalynology-the geological part of palynology-a lead over several other branches of palaeontology. A basic requirement, of course, is that one knows exactly how to interpret the record. This brings us back to the opening phrases. Whereas, in some respects, quite reliable conclusions can already be drawn, which can be to the benefit of other scientific fields as well, palynology still has very much to learn from its own work as well as from other branches of science. There is a continuous interaction. This special issue of the journal Palaeogeography, Palaeoclimatology, Palaeoecology will 
supply its readers with an evaluation and some examples of problems demonstrating this mutual interaction between scientific specializations. The purpose of this will be to examine the possibilities, problems, and limitations of palynology within the group of scientific branches which collectively might be called environmental geology.

\section{RELATION BETWEEN PALYNOLOGICAL ASSEMBLAGES AND NATURAL VEGETATIONS}

It is increasingly being realized that many ecological conclusions which in the past were drawn from pollen diagrams have depended on qualitative, intuitive interpretation of these diagrams and often on an overestimation of climatic conditions. There are several factors which hinder a palynological diagram from accurately reflecting the composition of the vegetation with regard to the time and place at which the assemblage was deposited. The most important of these factors are: differences in pollen or spore production between the various plant species, differences in pollen dispersal, variations in rate and manner of sedimentation, differences in pollen and spore preservation (cf. MANTEN, 1966b).

A modern approach to refining interpretations of palynological assemblages is the study of the relationship between recent surface samples from various areas and the vegetation of these areas. Unfortunately such studies can only be carried out where an undisturbed natural vegetation is still present over large areas. In densely populated regions, man-made "open" areas promote long-distance transport of pollen grains, and thinking in terms of natural vegetation, exotic and cultivated plants disturb the interpretation of the pollen spectra obtained from surface samples. The method is also difficult to apply to cases in which former vegetation developed under edaphic, climatic, or successional conditions which are not equivalent to anything found today, as in the revegetation of deglaciated landscapes. In general, however, the study of recent surface samples opens promising new perspectives.

An example of such work is to be found in the contribution to this journal issue made by $\mathbf{J}$. Terasmae. He shows how pollen-and-spore assemblages in surface samples collected in the Canadian Northwest Territories reflect the characteristics of the surrounding tundra vegetation. Terasmae also found that all samples contained pollen grains of spruce and pine, up to percentages of the total count of arboreal pollen which could be as high as 13 for spruce pollen and 35 for pine pollen. Surface wind directions account for this long-distance transport. A study of peat samples from the same area suggested that environmental conditions favourable to peat accumulation had established themselves in Late Postglacial time and also that since then meteorological conditions influencing long-distance pollen transport have remained essentially the same. 


\section{PALYNOLOGY AND METEOROLOGY}

The above-mentioned study by Terasmae thereby also reflects another modern development in palynology, namely an investigation of the influence of climatic and vegetation-structural conditions on pollen dispersal, and thus, also on the composition of the pollen diagram.

For many years palynologists have generally assumed that pollen grains and spores are predominantly transported to lakes and bogs in the following manner: considerable amounts of pollen grains are first carried to high altitudes by thermal convection currents, are spread over large areas, and later fall back on the earth in a more or less vertical descent. In addition, some direct pollen transfer from the shore or from the border vegetation was usually assumed to take place. For the supposed sedimentation of pollen grains, the term "pollen rain" is being used. As early as 1916, this term was used by Lennart von Post, when he gave his Christiania lecture (VoN POST, 1918) and the idea received wide distribution through the important palynological textbooks (ERdTMAN, 1943, p.1; FAEGri and IVERSEN, 1950, p.34).

TAUBER $(1965,1967)$ in particular has demonstrated that in most interpretations of pollen diagrams several aspects of pollen transfer, such as wind velocities, wind turbulence, terminal velocities of fall of pollen grains, and the physical structure of the vegetation are taken into account too little. From the meteorological side, SCHMIDT (1967) has also recently pointed out that palynologists should intensify their cooperation with meteorologists. A large amount of data for air motion and for the transport of airborne particles in the size range of pollen grains has been gathered since World War II. Foremost in the fields collecting this information were the study of air pollution, dissemination of insecticidal aerosols, and the dispersal of radioactive debris. The resultant knowledge was applied to palynology by Tauber. He demonstrated first that although large amounts of pollen are carried to high altitudes by convection currents, data from the fields mentioned above, as well as actual measurements of pollen drift, do not support the idea of a return of the pollen in the form of something like a pollen rain. The number of pollen grains caught from air currents on a vertical surface placed near the ground are, at normal wind velocities, ten to twenty times as numerous as the number of grains caught on the same surface if placed in a horizontal position. This shows that pollen grains follow wind currents and, like these, move most of the time in a predominantly horizontal direction.

Considering a predominantly horizontal pollen drift, pollen carried by the wind above the canopy of the forest can hardly be the main source of the large amounts of arboreal pollen which are actually deposited in small lakes and bogs. With the most common wind velocities $(1-10 \mathrm{~m} / \mathrm{sec})$, pollen from above the canopy will pass over the basins in a much shorter time than is required to fall 15-20 $\mathrm{m}$ down because of gravity, or to be mixed that distance downward by eddy 
diffusion. Tauber, therefore, pointed out that much pollen must be transported via the trunk space of deciduous forests. Air currents passing there have the most direct chance of both picking up pollen and of delivering it to the boundary layer above lakes or bogs (a more or less stagnant layer of air extending a fraction of a millimetre or a few millimetres above smooth surfaces). Thirdly, pollen is also brought down by rain, either as a true "rainout" (pollen grains already contained in the droplets of the clouds) or as a "washout" (due to scavenging of the air by falling rain drops); the latter being highly efficient in removing pollen from the air layer between the cloud layer and the surface of the earth.

These three main components of pollen deposition reflect the vegetation of areas of widely different extent. Pollen grains carried through the trunk space will originate mainly from within a few hundred metres; pollen carried above the canopy will reflect the vegetation within several kilometres, though with a rapidly decreasing efficiency at increasing distances. The rainout component will be even more regional. The shares of each of the three main components in the total pollen deposited in a lake or bog will vary with the size of the basin, with the denseness of the surrounding vegetation, and with climatic conditions.

From the pollen fraction transported through the vegetation, the large and heavy pollen grains (e.g., those of beech, elm and lime) are filtered off to a much greater extent than small grains. Changes in the denseness of the vegetation influence the velocities of air currents in the trunk space and, consequently, the distance of pollen transport. In cases of denser vegetation, heavy pollen grains and pollen from trees growing at comparatively long distances from a basin will, therefore, be affected most.

This new insight into the phenomenon of differential pollen dispersion was applied by TAUBER (1965) to explain the generally drastic fall in Ulmus-pollen percentages at the Atlantic-Subboreal transition. Earlier this elm-pollen fall has been explained either as a result of a climatic change or as the first indication of a utilization of forest trees for fodder in primitive agriculture (cf. MANTEN, 1966a, p.301). The main objection to the latter explanation is that the Ulmus-pollen decline is too widely distributed in northern European and also in Canadian pollen diagrams. On the other hand, the nature of the atmospheric circulation of the Northern Hemisphere makes a climatic parallelism between these regions likely (Nichols, 1967). Tauber believes that this climatic development consisted of the occurrence of a period with a rather severe dryness as its most dominating characteristic. This caused a lowering of the ground-water table, and, in connection with this, a change in the ecological equilibrium. On dried-up lake deposits, alder and willow would have expanded, forming a shelter belt around the remaining part of the basin. On the dried fringes of raised bogs similar shelter belts might be formed by shrubs of birch and willow. In both cases such a belt slowed down the wind velocities in the trunk space, thus reducing the area from which the trunkspace component of pollen is carried to the basin. At the same time there was 
increased pollen filtering. Since deciduous climax trees (beech, elm, lime) have large pollen grains, as compared to the smaller pollen grains of pioneer trees and light-demanding trees (alder, birch, hazel, ash), a filtering will always tend to change the pollen spectrum in such a way that the forest appears to have become more open and light, irrespective of actual changes in its composition.

These factors of shorter transport and increased filtering may have been, in Tauber's view, the main reasons for the Ulmus-pollen fall. In addition, elm is rather susceptible to changes in water supply due to a more horizontal root system and might have lost some of its area during an extended period of dryness.

\section{QUATERNARY PALYNOLOGY}

Pollen analysis started just over half a century ago with the application of the method to Quaternary deposits of Scandinavia, an area that had been glaciated during the Pleistocene and that was occupied by forests composed of only a limited number of tree species. In the course of time, the method was also applied to Quaternary deposits elsewhere. In many of these cases, the pollen spectra were more complicated because of a much richer and varied vegetation and/or a more pronounced relief of the landscape. Although a wealth of Quaternary pollen diagrams has already been published, there are still many gaps, as well as spots which need further refinement, in the world-wide picture of plant geography during the various successive Quaternary stages.

The paper by M. Tsukada, in this issue, is one example of the many studies on this period still being carried out today. It emphasizes palaeoclimatological and palaeoecological conclusions which can be drawn from pollen studies. In addition, it also shows how Quaternary palynology produces evidence of use in archaeology.

In another example of Quaternary palynological work, P. A. Colinvaux also demonstrates a more palaeogeographical aspect. He shows that during the Late Glacial a land bridge existed between Siberia and Alaska. St. Lawrence Island is a remnant of this earlier intercontinental connection. Colinvaux' pollen analyses also show that the area during Late Glacial time was covered with a tundra with a more arctic character than the one found there today.

A phytogeographical study concerning the distribution of coniferous genera in Europe in both the Quaternary and Tertiary has been contributed to this issue by $\mathrm{D}$. K. Ferguson. It is based on both macroscopic and microscopic plant fossils.

With increasing knowledge of the succession of events which took place during the Quaternary Period in various parts of the world, the question became more urgent as to how the events in widely separated areas were to be correlated. Stratigraphical studies based on mammal fossils, radiometric-age determinations or comparison of pollen diagrams cannot solve these chronostratigraphical 
problems alone. Combined studies are necessary. In this connection, fluorescence analysis of pollen may become a most important tool, as P. van Gijzel, Th. van der Hammen and T. A. Wijmstra demonstrate in a joint paper in this issue. Studies of the various ways in which use can be made of the natural property of pollen grains and spores to transform short-wave ultraviolet light, to which the grains are exposed, into light within the visible range of the spectrum have been very successful. This direction of research has been followed by Van Gijzel since 1961 (cf. VAN GiJzeL, 1967).

Another modern development in palynology is the study of spores and pollen grains contained in sediments of sea and ocean floors. It enables correlations between these sediments and those found on the surrounding land. It also offers a most promising chance to obtain a continuous record of major vegetational and climatic changes which took place during the Quaternary Period. Details can be found in another special journal issue (MANTEN, 1966c).

\section{PRE-QUATERNARY PALYNOLOGY}

In the course of time, palynology has also extended its activities more and more to deposits of pre-Quaternary age. This advanced new problems. For plants that lived during the Holocene and Pleistocene, it could more or less safely be assumed that their physical requirements and tolerances were similar to those of their present-day relatives. Such an extrapolation becomes more dangerous for geologically older plants, even if their pollen grains or spores show close similarity to pollen grains or spores of plants still living today. In addition, the number of plant microfossils of which the natural-systematic identity can be reliably determined and the number of plants still having recent relatives decreases with increasing geological age. Thirdly, the fluctuations recorded in pollen diagrams of pre-Quaternary sedimentary successions are often less pronounced than those from the Quaternary, and it is not always clear whether these have to be ascribed to climatic factors or to one or more of several other possible causes.

In order to cope with this drawback of pre-Quaternary palynology, cooperation has to be sought, wherever possible, with other fields of geo-scientific research. Thus macropalaeobotanical, sedimentological and geomorphological studies revealed that quantitative fluctuations observed in Miocene pollen diagrams, and which initially had been explained as facies differences, probably were caused mainly by climatically induced movement of floral areas (cf. SITTLER, 1967; VON DER BRELIE, 1967).

Independent from work carried out in Germany, E. Nagy studied the vegetation which existed in Hungary during successive Miocene stages covering a stratigraphic range which comprises the palynological zones $D-G$ of VON DER BRELIE (1967). As appears from her contribution to this journal issue, she followed 
a more interpretative palynological path in making palaeoclimatological deductions. She, too, suggests that differences in humidity and temperature occurred during the Miocene. The observation that there is no very distinct correlation between the results of the two authors demonstrates the necessity for more palynological and palaeoclimatological studies of the Neogene.

N. J. Norton and J. W. Hall found that at least in mid-continental U.S.A. the quantitative ratio between pollen grains of angiosperms and those of gymnosperms may assist in the distinction between uppermost Cretaceous and lowermost Tertiary deposits. The percentage of dicotyledonous pollen grains declines and that of gymnospermous grains rises. The two authors are not certain what caused this significant floristic change but are inclined to think of climatic reasons.

ZAKLINSKAIA (1967) recently studied the microfloral remains from the Late Cretaceous and the Palaeogene on a more world-wide scale. She reported that everywhere a Maastrichtian flora (as present in the Hell Creek Formation in North America) was followed by a Danian-Paleocene flora of rather different composition. The latter flora was differentiated in a number of floristic subregions. The latter may again show some climatic differentiation, with a flora reflecting a more thermophilic character in southern latitudes and a contemporaneous flora which developed under warm-temperate and drier conditions further north, as reported by SAMOILOVICH (1967) for the East Siberian phytogeographical subregion.

Because of the great abundance and variety of plant microfossils found in an Upper Cretaceous series of strata in Canada, S. K. Srivastava, in a paper in this journal issue, accepted the risk and dared to make comparisons with the ecology of probably related present-day plants, thus extrapolating over a time lapse in the order of not less than about seventy million years. He identified spores and pollen grains of at least thirty families. Many of his palaeoecological deductions mutually support each other. A temporary cooling of the climate is suggested, probably caused by volcanic dust in the atmosphere, which decreased the amount of solar radiation that reached the surface of the earth. The beds laid down during the cooler stages are rich in bentonite.

D. Habib and P.K.H. Groth, in a contribution to this journal issue, report a comparison of palynological data from Carboniferous deposits with lithological invertebrate-palaeontological and geochemical data from those same deposits. They show how an initially fairly dry area with a vegetation of Endosporites-producing lycopods and gymnospermous plants was invaded by a peat swamp in which Lycospora-producing lycopods were the dominant vegetational element. When the swamp became more brackish, these lycopods migrated towards the landward margin of the swamp and were replaced at their earlier sites by Densosporites-producing lycopods which probably had more salinity tolerance.

The paper by P. M. Corsin, R. Coquel and S. Loboziak is again of another nature. It demonstrates how palynologists try to refine their work and attempt to obtain as accurate an insight as possible into the conditions under which ancient 
sediments were deposited. Much work still remains, especially in the application of palynology to detailed geological problems.

PALYNOLOGY AND LARGE-SCALE PALAEOGEOGRAPHICAL CONCEPTS

A confrontation of palynological information with conclusions drawn from work in other geological disciplines is at this time still generally easiest when dealing with large-scale concepts. A classical example is the idea of continental drift. Many palynological data have been produced to support this concept. For examples of such studies, reference is made to two recent papers by Sullivan $(1965,1967)$ who studied Carbonaceous microfloras from Europe and North America. He found that these reflect a geographical differentiation which can be divided into three main floral provinces. Superimposition of the distribution of these provinces on a map showing palaeomagnetically determined palaeolatitudes showed that spore floras of a similar composition everywhere occupy the same latitudinal belt, thus suggesting a climatic zonation.

VAN HiLTen (1964) supposes that during the Permian and Early Mesozoic the continental masses were united in two separate blocks, a northern (Laurasia) and a southern one (Gondwanaland). Palaeomagnetic data from northeastern Italy, southern France and northern Spain make it likely that the present Alpine units of Europe at that time still formed part of Africa, that is, of the Gondwanaland block. Van Hilten further assumes that the two large continental blocks later sheared along one another in a dextral-slip movement. He called this the Tethys twist. A clockwise character of the shearing between the blocks is suggested by the many dextral strike-slip faults found in the Tethys shear zone, and by the dextral movement with respect to Laurasian Europe of several alpine tectonic units through this shear zone. This wrenching movement may have caused the twisting of the alpine chains into the garlands which are so characteristic of the Tethys zone. These views of Van Hilten are tested palynologically in this issue by $\mathrm{H}$. Visscher who studied the composition of plant-microfossil assemblages of Permian and Triassic age from both the supposed Gondwana and Laurasian parts of Europe. In contrast to what could be expected if the concept of a Tethys twist is accepted, striking similarities were found to exist between the various assemblages.

\section{FINAL REMARKS}

Elsewhere (MANTEN, 1967b, pp.63-64, 65) it has been announced that two other contributions would also appear in this journal issue, one by J. B. Richardson and one by L. R. Wilson. However, the full texts of these had not been received when this issue went to press. In order not to delay excessively publication of the 
remaing contributions, these two regretfully had to be omitted. It is hoped that they can be presented to the readers of this journal in a later, regular issue.

The papers contained in this special issue and the few others to which reference is made in this introductory article represent only a small fraction of the large volume of palynological work which has been carried out in recent years. They do not approach an exhaustive demonstration of the contribution which palynology may make to environmental geology, but rather serve to give a general impression at the hand of normal research reports. It is hoped that this journal issue may promote the appreciation of palynology by workers in other fields of the earth sciences and may stimulate a further increase in cooperation between them and the palynologists.

\section{REFERENCES}

Erdtman, G., 1943. An Introduction to Pollen Analysis. Chronica Botanica Co., Waltham, Mass., 239 pp. (2 ed. 1954).

FAEGRI, K. and IVERSEN, J., 1950. Textbook of Modern Pollen Analysis. Munksgaard, Copenhagen, 168 pp. (2 ed. 1964).

Manten, A. A., 1966a. Half a century of modern palynology. Earth-Sci. Rev., 2(4): 277-316.

Manten, A. A., 1966b. Some current trends in palynology. Earth-Sci. Rev., 2(4): 317-343.

Manten, A. A. (Editor), 1966c. Marine Palynology-Marine Geol., 4(6): 383-582.

Manten, A. A., 1967a. Lennart von Post and the foundation of modern palynology. Rev. Palaeobotan. Palynol., 1: 11-22.

Manten, A. A., 1967b. Palaeophytic and Mesophytic palynology at the Utrecht conference. Rev. Palaeobotan. Palynol., 1: 61-68.

Nichols, H., 1967. Central Canadian palynology and its relevance to northwestern Europe in the Late Quaternary Period. Rev. Palaeobotan. Palynol., 2: 231-243.

Samoilovich, S. R., 1967. Tentative botanico-geographical subdivision of northern Asia in Late Cretaceous time. Rev. Palaeobotan. Palynol., 2: 127-139.

Schmidt, F. H., 1967. Palynology and meteorology, Rev. Palaeobotan. Palynol, 3: 27-47.

SitTler, C., 1967. Mise en évidence d'un réchauffement climatique à la limite de l'Oligocène et du Miocène. Rev. Palaeobotan. Palynol., 2: 163-172.

Sullivan, H. J., 1965. Palynological evidence concerning the regional differentiation of Upper Mississippian floras. Pollen Spores, 7(3): 539-563.

Sullivan, H. J., 1967. Regional differences in Mississippian spore assemblages. Rev. Palaeobotan. Palynol., 1: 185-192.

TAUBER, H., 1965. Differential pollen dispersion and the interpretation of pollen diagrams. Danmarks Geol. Undersogelse, II, 89: 1-69.

TAUBER, H., 1967. Investigations of the mode of pollen transfer in forested areas. Rev. Palaeobotan. Palynol., 3: in press.

VAn GiJzel, P., 1967. Palynology and fluorescence microscopy. Rev. Palaeobotan. Palynol, 2: 49-79.

VAN HiLTEN, D., 1964. Evaluation of some geotectonic hypotheses by palaeomagnetism. Tectonophysics, 1(1): 3-71.

VoN DER BRELIE, G., 1967. Quantitative Sporenuntersuchungen zur stratigraphischen Gliederung des Neogens in Mitteleuropa. Rev. Palaeobotan. Palynol., 2: 147-162.

Von Post, L., 1918. Skogsträdpollen i sydsvenska torvmosselagerföljder. Förh. Skand. Naturforskeres 16. møte, 1916, pp. 432-465.

ZakLINSKAIA, E. D., 1967. Palynological studies on Late Cretaceous-Palaeogene floral history and stratigraphy. Rev. Palaeobotan. Palynol., 2: 141-146. 